\title{
Atherosclerosis profile and incidence of cardiovascular events: a population-based survey Jennifer G Robinson ${ }^{1}$, Kathleen M Fox*2, Michael F Bullano ${ }^{3}$, Susan Grandy ${ }^{3}$ for the SHIELD Study Group
}

Address: ${ }^{1}$ Department of Medicine, University of Iowa, Iowa City, IA, USA, ${ }^{2}$ Strategic Healthcare Solutions, LLC, Monkton, MD, USA and ${ }^{3}$ Health Economics and Outcomes Research, AstraZeneca Pharmaceuticals LP, Wilmington, DE, USA

Email: Jennifer G Robinson - jennifer-g-robinson@uiowa.edu; Kathleen M Fox* - kathyfox@comcast.net; Michael F Bullano - michael.bullano@astrazeneca.com; Susan Grandy - susan.grandy@astrazeneca.com; the SHIELD Study Group - not@valid.com

* Corresponding author

Published: 15 September 2009

BMC Cardiovascular Disorders 2009, 9:46 doi:10.1 186/I47|-226I-9-46
Received: 10 June 2009

Accepted: 15 September 2009

This article is available from: http://www.biomedcentral.com/I47I-226I/9/46

(c) 2009 Robinson et al; licensee BioMed Central Ltd.

This is an Open Access article distributed under the terms of the Creative Commons Attribution License (http://creativecommons.org/licenses/by/2.0), which permits unrestricted use, distribution, and reproduction in any medium, provided the original work is properly cited.

\begin{abstract}
Background: Atherosclerosis is a chronic progressive disease often presenting as clinical cardiovascular disease (CVD) events. This study evaluated the characteristics of individuals with a diagnosis of atherosclerosis and estimated the incidence of CVD events to assist in the early identification of high-risk individuals.
\end{abstract}

Methods: Respondents to the US SHIELD baseline survey were followed for 2 years to observe incident self-reported CVD. Respondents had subclinical atherosclerosis if they reported a diagnosis of narrow or blocked arteries/carotid artery disease without a past clinical CVD event (heart attack, stroke or revascularization). Characteristics of those with atherosclerosis and incident CVD were compared with those who did not report atherosclerosis at baseline but had CVD in the following 2 years using chi-square tests. Logistic regression model identified characteristics associated with atherosclerosis and incident events.

Results: Of 17,640 respondents, 488 (2.8\%) reported having subclinical atherosclerosis at baseline. Subclinical atherosclerosis was associated with age, male gender, dyslipidemia, circulation problems, hypertension, past smoker, and a cholesterol test in past year $(O R=2.2)$ [all $p<0.05$ ]. Incident CVD was twice as high in respondents with subclinical atherosclerosis $(25.8 \%)$ as in those without atherosclerosis or clinical CVD (I2.2\%). In individuals with subclinical atherosclerosis, men $(R R=1.77, p=0.050)$ and individuals with circulation problems $(R R=2.36, p=0.003)$ were at greatest risk of experiencing CVD events in the next 2 years.

Conclusion: Self-report of subclinical atherosclerosis identified an extremely high-risk group with a $>25 \%$ risk of a CVD event in the next 2 years. These characteristics may be useful for identifying individuals for more aggressive diagnostic and therapeutic efforts.

\section{Background}

Clinical manifestations of atherosclerosis, including coronary artery disease, cerebrovascular disease, and periph- eral arterial disease, will occur in 2 of 3 men and 1 in 2 women after age 40 . [1] Almost $60 \%$ of deaths are due to a cardiovascular disease (CVD) cause. Atherosclerosis is a 
chronic, progressive disease with a long asymptomatic phase. [2] Subclinical atherosclerosis is a latent precursor of clinical CVD, including myocardial infarction (MI) and stroke. [3]

The Healthy People 2010 initiative and the Public Health Action Plan to Prevent Heart Disease and Stroke call for improving cardiovascular health through prevention, detection, and treatment of risk factors, as well as prevention of recurrent CVD events. [4-6] The American Heart Association (AHA) guidelines for primary and secondary prevention of atherosclerotic CVD provide evidence and recommendations to assist clinicians in managing and treating atherosclerosis. [7-9] However, evidence is limited on identifying individuals with subclinical atherosclerosis before a CVD event occurs, especially since specialized diagnostic imaging is not part of routine clinical practice. The purpose of the present study was to evaluate the self-reported characteristics and estimate the incidence of CVD events among individuals with subclinical atherosclerosis to assist in the early identification of high-risk individuals.

\section{Methods}

A cohort of individuals with a diagnosis of subclinical atherosclerosis with no prior history of CVD events (i.e., MI, stroke, or revascularization) was identified from the Study to Help Improve Early evaluation and management of risk factors Leading to Diabetes (SHIELD) and compared with SHIELD individuals without reported atherosclerosis and no prior history of CVD events. SHIELD included an initial screening phase to identify cases of interest in the general population and a detailed baseline survey to follow up identified cases for health status, health knowledge, attitudes, behaviors, and treatment. Annual follow-up surveys were administered to obtain changes in health status, behaviors and treatment. A detailed description of the SHIELD methodology has been published previously. [10,11]

In brief, the screening survey was mailed to a stratified random sample of 200,000 US households, representative of the US population for geographic residence, household size and income, and age of head of household. [12] The head of household provided responses for up to 4 adult (aged $\geq 18$ years) household members, resulting in a response rate of $63.7 \%(127,420$ households for 211,097 adults). The baseline survey was sent in 2004 to 22,001 individuals, a stratified random sample of screening respondents, who self-reported diabetes mellitus or cardiometabolic risk factors. Each respondent group was balanced to be representative of that population (e.g. type 1 diabetes, type 2 diabetes) for age, gender, geographic region, household size and income as the US population. A response rate of $71.8 \%$ was obtained $(n=15,794)$.
In August 2005, the first annual follow-up survey was mailed to all individuals selected for the baseline survey who were still enrolled in the household panel ( $\mathrm{n}=$ $19,613)$. The second follow-up survey was mailed in July 2006 to individuals who had returned either the baseline and/or first annual questionnaires $(n=18,445)$. The 2005 survey had a response rate of $72 \%$, and a $75 \%$ response rate was obtained for the 2006 survey $(n=13,877)$. This study utilized the baseline, 2005, and 2006 survey responses.

\section{Study Population}

Respondents to the baseline survey were considered to have subclinical atherosclerosis if they reported a diagnosis of narrow or blocked arteries or carotid artery disease without a past clinical CVD event (heart disease, heart attack, stroke, angioplasty, or heart bypass surgery) based on the survey question of "have you ever been told by a doctor, nurse or other health professional that you have narrow or blocked arteries/carotid artery disease". Respondents were also asked if they "had ever been told that you have heart disease/heart attack, stroke/TIA or had angioplasty, stents or surgery to clear your arteries or heart bypass surgery". The comparison cohort for the cross-sectional analysis was composed of individuals who did not report a diagnosis of atherosclerosis (subclinical) and/or clinical CVD (i.e. no prior history of CVD event) in the baseline survey.

\section{CVD Events}

CVD events included heart attack, stroke, angioplasty, or heart bypass surgery. An incident CVD event was defined as a new CVD event reported in either the 2005 or 2006 survey without a history of a CVD event from the baseline survey. Respondents who completed the baseline, 2005, and 2006 surveys and responded positively to the survey questions for atherosclerosis and CVD events $(n=7,483)$ were included in the analysis of incident CVD events.

Respondents were asked to provide their weight and height for calculation of body mass index. They also were provided a measuring tape and instructed that while standing, hold the tape measure loosely around their waist at the level of their navel ("belly button") to determine waist circumference. Respondents were asked whether they "had ever been told by a doctor, nurse or health professional that you had circulation problems of any kind (categorized as circulation problems) or cholesterol problems" (categorized as dyslipidemia).

\section{Statistical Analysis}

Two separate analyses were conducted: 1) cross-sectional analysis of baseline respondents for prevalence and characteristics predicting atherosclerosis, and 2) longitudinal analysis of incident CV events. Prevalence of subclinical 
atherosclerosis was calculated as the number of individuals reporting a diagnosis of atherosclerosis at the baseline survey divided by the total number of respondents to the baseline survey. Incidence of CVD events was quantified as the number of new CVD events that were reported during the 2 years of follow-up since the baseline survey. Demographic features, comorbid conditions, obesity, and smoking history of individuals with subclinical atherosclerosis were compared with those of the cohort who did not report a diagnosis of atherosclerosis or previous CVD event, using two-sided chi-square tests. Similar comparisons were made between respondents with atherosclerosis and incident CVD events and the respondents with no atherosclerosis but who had an incident CVD event.

Logistic regression analyses identified characteristics associated with atherosclerosis without prior history of CVD event and atherosclerosis with incident CVD events. To identify characteristics of subclinical atherosclerosis, the regression model included individuals with and without subclinical atherosclerosis from the baseline survey as the dependent variable and age, gender, race, household income, education, geographic region, dyslipidemia, circulation problems, diabetes mellitus, hypertension, abdominal obesity, smoking, and cholesterol test in past year as independent variables. To identify characteristics of those with subclinical atherosclerosis who experienced incident CVD events, the regression model included respondents with incident CVD events and atherosclerosis, and age, gender, dyslipidemia, circulation problems, diabetes mellitus, hypertension, and smoking were independent variables. A second regression model was computed with respondents with incident CVD events as the dependent variable and atherosclerosis (yes/no), age, gender, dyslipidemia, circulation problems, diabetes, hypertension, and smoking as independent variables to ascertain the value of self-reported atherosclerosis for predicting incident CVD events. Statistical significance was set $a$ priori at $\mathrm{p}<0.05$. The regression model c-statistic was computed to assess goodness of fit for each model.

\section{Results \\ Prevalence and Characteristics of Subclinical Atherosclerosis: Cross-sectional analysis}

The prevalence of subclinical atherosclerosis was $2.8 \%$ in the baseline survey (488 individuals out of 17,640 respondents). Of the 17,640 respondents, $13,596 \mathrm{did}$ not report a diagnosis of atherosclerosis or prior CVD event and were classified as the comparison cohort, and 3,556 reported having a prior CVD event and were excluded. Individuals reporting an atherosclerosis diagnosis were significantly older, male, less educated, and had lower income than respondents without atherosclerosis diagnosis or CVD event history $(\mathrm{p}<0.01)$ (Table 1$)$. Those reporting subclinical atherosclerosis were also more likely to report dyslipidemia, circulation problems, diabetes mellitus, hypertension, abdominal obesity, a cholesterol test in the past year, or past smoking.

In the multivariate model, subclinical atherosclerosis was associated with advancing age, male gender, geographic region, dyslipidemia, circulation problems, hypertension, and smoking (Table 2). The model c-statistic was 0.964 (p $<0.05$ ). The odds of atherosclerosis increased by $60 \%$ with each decade of increasing age and were twice as high in men. Most US geographic regions had more than twice the odds of atherosclerosis compared with the Pacific region. Respondents with dyslipidemia were 2 times and those with circulation problems were 5 times more likely to have subclinical atherosclerosis than those without these comorbid conditions. Respondents with hypertension or who were smokers (current or past) had a $40 \%$ $74 \%$ increased odds of having atherosclerosis. Individuals with diabetes mellitus were less likely to have atherosclerosis. Race, household income, education, abdominal obesity, and having a recent cholesterol test were not predictive of atherosclerosis ( $p>0.05$ for all).

Incident CVD Events and Predictors: Longitudinal analysis A total of 7,483 respondents completed the baseline, 2005, and 2006 surveys and answered the questions on atherosclerosis and CVD events. Among this sample of respondents, 291 individuals had subclinical atherosclerosis at baseline. Of the 291 individuals with atherosclerosis, 75 (25.8\%) respondents reported an incident CVD event during the following 2 years. For the respondents without atherosclerosis at baseline ( $\mathrm{n}=7,192), 878$ (12.2\%) individuals had an incident CVD event over the 2 years. The relative risk of incident CVD event after adjustment for age, gender, comorbid conditions, and smoking was 2.9 (95\% CI: 2.2-3.85) for those reporting atherosclerosis.

Among individuals who experienced a CVD event during the 2-year follow-up, a significantly greater proportion of respondents with subclinical atherosclerosis were men, and reported a diagnosis of dyslipidemia, circulation problems, or hypertension compared with respondents without subclinical atherosclerosis $(\mathrm{p}<0.05)$ (Table 3$)$. Significantly fewer respondents with subclinical atherosclerosis reported diabetes mellitus compared with respondents without clinical atherosclerosis $(\mathrm{p}<0.05)$. Most respondents $(>83 \%)$ reported having a cholesterol test in the past 12 months; however, significantly more respondents with atherosclerosis and incident CVD event had a cholesterol test $(93 \%)(\mathrm{p}<0.05)$. There was no difference between respondents with subclinical atherosclerosis and individuals without atherosclerosis for race, household income, geographic region, obesity, or smoking (Table 3). 
Table I: Comparison of respondents reporting diagnosis of atherosclerosis without history of CVD event in the baseline survey versus respondents with no diagnosis of atherosclerosis and no history of CVD event

\begin{tabular}{|c|c|c|}
\hline Characteristics & $\begin{array}{l}\text { Atherosclerosis at baseline } \\
\qquad(n=488)\end{array}$ & $\begin{array}{l}\text { No atherosclerosis at baseline } \\
\qquad(n=13,596)\end{array}$ \\
\hline Age, years, mean (SD) & $66.9(12.8)^{*}$ & $51.3(15.6)$ \\
\hline Men, n (\%) & $276(56.6 \%)^{*}$ & 4885 (35.9\%) \\
\hline \multicolumn{3}{|l|}{ Race, n (\%) } \\
\hline White & 431 (88.3\%) & II,779 (86.6\%) \\
\hline Black & $34(7.0 \%)$ & $1025(7.5 \%)$ \\
\hline Other & $9(1.8 \%)$ & $384(2.8 \%)$ \\
\hline \multicolumn{3}{|l|}{ Income, n (\%) } \\
\hline$>\$ 22,500-\$ 39,999$ & $259(53.1 \%)^{*}$ & $5718(42.1 \%)$ \\
\hline$\$ 40,000-\$ 89,999$ & $153(31.3 \%)$ & $5144(37.8 \%)$ \\
\hline$\geq \$ 90,000$ & $76(15.6 \%)$ & $2734(20.1 \%)$ \\
\hline \multicolumn{3}{|l|}{ Geographic region, $\mathbf{n}(\%)$} \\
\hline Northeast & $116(23.8 \%)^{*}$ & $2612(19.2 \%)$ \\
\hline North Central & $120(24.6 \%)$ & $3372(24.8 \%)$ \\
\hline South Atlantic & $108(22.1 \%)$ & $2592(19.1 \%)$ \\
\hline South Central & $85(17.4 \%)$ & 2258 (16.6\%) \\
\hline Mountain & $19(3.9 \%)$ & $901(6.6 \%)$ \\
\hline Pacific & 40 (8.2\%) & $186 \mid(13.7 \%)$ \\
\hline \multicolumn{3}{|l|}{ Education, n (\%) } \\
\hline$<8^{\text {th }}$ grade-High school GED & $174(35.8 \%)^{*}$ & 3949 (29.4\%) \\
\hline Some college-college graduate & $253(52.1 \%)$ & $7660(57.0 \%)$ \\
\hline Graduate degree & $59(12.1 \%)$ & $1835(13.6 \%)$ \\
\hline Dyslipidemia diagnosis, n (\%) & $40 \mathrm{I}(82.2 \%)^{*}$ & 6501 (47.8\%) \\
\hline Circulation problem diagnosis, $\mathbf{n}(\%)$ & $201(41.2 \%)^{*}$ & II $84(8.7 \%)$ \\
\hline Diabetes diagnosis, n (\%) & $180(36.9 \%)^{*}$ & $4243(31.2 \%)$ \\
\hline Hypertension diagnosis, $\mathbf{n}(\%)$ & $375(76.8 \%)^{*}$ & $5796(42.6 \%)$ \\
\hline \multicolumn{3}{|l|}{ BMI category, n (\%) } \\
\hline Underweight & $2(0.4 \%)$ & $175(1.3 \%)$ \\
\hline Normal weight & $71(14.8 \%)^{*}$ & $2889(21.6 \%)$ \\
\hline Overweight & $157(32.7 \%)$ & $3893(29.1 \%)$ \\
\hline Obese & $250(52.1 \%)$ & $6417(48.0 \%)$ \\
\hline Abdominal obesity (waist circumference), n (\%)† & $386(85.4 \%)^{*}$ & 8948 (70.9\%) \\
\hline Cholesterol test in past year, $n(\%) \dagger$ & $447(94.3 \%)^{*}$ & 8943 (71.1\%) \\
\hline \multicolumn{3}{|l|}{ Smoking, n (\%) } \\
\hline Current smoker & $83(17.4 \%)$ & $2416(18.0 \%)$ \\
\hline Past smoker & $235(49.2 \%)^{*}$ & $3848(28.7 \%)$ \\
\hline Never smoked & $160(33.5 \%)$ & $7 \mid 47$ (53.3\%) \\
\hline
\end{tabular}

*Chi-square $\mathrm{p}<0.01$; $\nmid$ Group $\mathrm{n}$ slightly less than other variables

$\mathrm{BMI}=$ body mass index; $\mathrm{CVD}=$ cardiovascular disease; $\mathrm{GED}=$ general equivalency diploma 
Table 2: Logistic regression odds ratios for predictors of subclinical atherosclerosis (no history of prior CVD event) among SHIELD respondents $(n=9,672)$

\begin{tabular}{|c|c|c|}
\hline Characteristics & Odds Ratio $(95 \% \mathrm{Cl})$ & P value \\
\hline Age (per year) & $1.06(1.05-1.07)$ & $<0.0001$ \\
\hline Gender, male (female is reference group) & $2.24(1.80-2.80)$ & $<0.0001$ \\
\hline Race, white (Other is reference group) & $0.65(0.32-1.34)$ & 0.24 \\
\hline Race, black (Other is reference group) & $0.69(0.31-1.55)$ & 0.37 \\
\hline Income, $<\$ 22,500$ ( $\geq \$ 90,000$ is reference group) & $1.03(0.72-1.48)$ & 0.87 \\
\hline Income, $\$ 22,500-\$ 39,999$ & $1.04(0.73-1.48)$ & 0.83 \\
\hline Income, $\$ 40,000-\$ 59,999$ & $0.94(0.65-1.35)$ & 0.74 \\
\hline Income, $\$ 60,000-\$ 89,999$ & $0.91(0.63-1.31)$ & 0.61 \\
\hline Geographic region, New England (Pacific is reference group) & $2.08(1.17-3.69)$ & 0.013 \\
\hline Geographic region, Middle Atlantic & $2.64(1.71-4.09)$ & $<0.0001$ \\
\hline Geographic region, East North Central & $2.40(1.56-3.69)$ & $<0.0001$ \\
\hline Geographic region, West North Central & $1.59(0.89-2.83)$ & 0.12 \\
\hline Geographic region, South Atlantic & $2.06(1.35-3.14)$ & 0.001 \\
\hline Geographic region, East South Central & $2.53(1.48-4.35)$ & 0.001 \\
\hline Geographic region, West South Central & $1.96(1.21-3.17)$ & 0.006 \\
\hline Geographic region, Mountain & $1.24(0.67-2.30)$ & 0.49 \\
\hline Education, $8^{\text {th }}$ grade (graduate degree is reference group) & $1.08(0.50-2.32)$ & 0.85 \\
\hline Education, some high school & $1.04(0.58-1.86)$ & 0.90 \\
\hline Education, high school graduate & $1.29(0.88-1.89)$ & 0.19 \\
\hline Education, some college & $1.40(0.98-2.00)$ & 0.06 \\
\hline Education, college graduate & $1.05(0.7 \mid-1.55)$ & 0.80 \\
\hline Dyslipidemia (cholesterol problems), Yes (No is reference group) & $2.04(1.56-2.69)$ & $<0.0001$ \\
\hline Circulation problems, Yes (No is reference group) & $4.95(3.95-6.21)$ & $<0.0001$ \\
\hline Diabetes, Yes (No is reference group) & $0.79(0.64-0.99)$ & 0.038 \\
\hline Hypertension, Yes (No is reference group) & $1.74(1.36-2.24)$ & $<0.0001$ \\
\hline Abdominal obesity (waist circumference), Yes & $0.80(0.59-1.08)$ & 0.14 \\
\hline Current smoker (Never smoked is reference group) & $1.40(1.02-1.91)$ & 0.037 \\
\hline Past smoker & $1.47(1.16-1.86)$ & 0.002 \\
\hline Cholesterol test in past year (Never is reference group) & $1.23(0.35-4.32)$ & 0.75 \\
\hline
\end{tabular}

Model correctly identified $96.4 \%$ of atherosclerosis respondents (c-statistic).

CVD = cardiovascular disease 
Table 3: Comparison of respondents with and without subclinical atherosclerosis at baseline but who experience an incident CVD event during 2 years of follow-up

\begin{tabular}{|c|c|c|}
\hline Characteristics & $\begin{array}{c}\text { Atherosclerosis at baseline }+ \text { incident } \\
\text { CVD event } \\
(n=75)\end{array}$ & $\begin{array}{l}\text { No Atherosclerosis at baseline }+ \text { incident } \\
\text { CVD event } \\
(n=878)\end{array}$ \\
\hline Age, years, mean (SD) & $68.1(11.2)^{*}$ & $59.0(14.5)$ \\
\hline Male, n (\%) & $44(58.7 \%)^{*}$ & $303(34.5 \%)$ \\
\hline \multicolumn{3}{|l|}{ Race, n (\%) } \\
\hline White & $64(85.3 \%)$ & $748(85.2 \%)$ \\
\hline Black & $3(4.0 \%)$ & $79(9.0 \%)$ \\
\hline Other & $2(2.7 \%)$ & $14(1.6 \%)$ \\
\hline Income $\geq \$ 40,000, n(\%)$ & $38(50.7 \%)$ & $408(46.5 \%)$ \\
\hline \multicolumn{3}{|l|}{ Geographic region, $\mathrm{n}(\%)$} \\
\hline Northeast & $13(17.3 \%)$ & $189(21.5 \%)$ \\
\hline South Atlantic & $17(22.7 \%)$ & $189(21.5 \%)$ \\
\hline Central & $35(46.7 \%)$ & $357(40.7 \%)$ \\
\hline Mountain & $4(5.3 \%)$ & $53(6.0 \%)$ \\
\hline Pacific & $6(8.0 \%)$ & $90(10.3 \%)$ \\
\hline Dyslipidemia diagnosis, n (\%) & $61(81.3 \%)^{*}$ & $549(62.5 \%)$ \\
\hline Circulation problem diagnosis, $\mathbf{n}(\%)$ & $39(52.0 \%)^{*}$ & $136(15.5 \%)$ \\
\hline Diabetes diagnosis, $\mathbf{n}(\%)$ & $22(29.3 \%)^{*}$ & $378(43.1 \%)$ \\
\hline Hypertension diagnosis, $\mathbf{n}(\%)$ & $60(80.0 \%)^{*}$ & $565(64.4 \%)$ \\
\hline \multicolumn{3}{|l|}{ BMI category, n (\%) } \\
\hline Underweight & 0 & $9(1.1 \%)$ \\
\hline Normal weight & $8(11.1 \%)$ & $123(14.4 \%)$ \\
\hline Overweight & $30(41.7 \%)$ & $237(27.7 \%)$ \\
\hline Obese & $34(47.2 \%)$ & $486(56.8 \%)$ \\
\hline $\begin{array}{l}\text { Abdominal obesity (waist } \\
\text { circumference), n (\%) } \dagger\end{array}$ & $43(84.3 \%)$ & $385(79.4 \%)$ \\
\hline Cholesterol test in past year, n (\%)† & $67(93.1 \%)^{*}$ & $670(83.1 \%)$ \\
\hline \multicolumn{3}{|l|}{ Smoking, n (\%) } \\
\hline Current smoker & $15(20.0 \%)$ & $152(17.5 \%)$ \\
\hline Past smoker & $34(45.3 \%)$ & $304(35.1 \%)$ \\
\hline Never smoked & $26(34.7 \%)$ & $4 I I(47.4 \%)$ \\
\hline
\end{tabular}

$*_{p}<0.05$; † Group $n$ slightly less than other variables

$\mathrm{BMI}=$ body mass index; $\mathrm{CVD}=$ cardiovascular disease

Multivariate logistic regression analyses of those with subclinical atherosclerosis demonstrated that men with atherosclerosis had a $77 \%$ greater risk of incident CVD event than women $(\mathrm{p}=0.05)$ (Figure 1$)$. The risk of incident CVD events increased 2.4 times among those with circulation problems compared with respondents without circulation problems $(p=0.003)$ (Figure 1$)$. In a second logistic regression model which assessed the value of selfreported atherosclerosis for predicting incident CVD events, the presence of atherosclerosis increased the risk of incident CVD events by 2.9 times $(\mathrm{p}<0.001)$ while controlling for other covariates. Increasing age $(\mathrm{RR}=1.01 \mathrm{per}$ year), type 2 diabetes $(\mathrm{RR}=1.37$ ), and hypertension ( $\mathrm{RR}$ $=1.54$ ) also significantly increased the risk of CVD events in this model $(\mathrm{p}<0.01)$ while gender, dyslipidemia, circulation problems, and smoking were not significant predictors after adjusting for atherosclerosis status. 


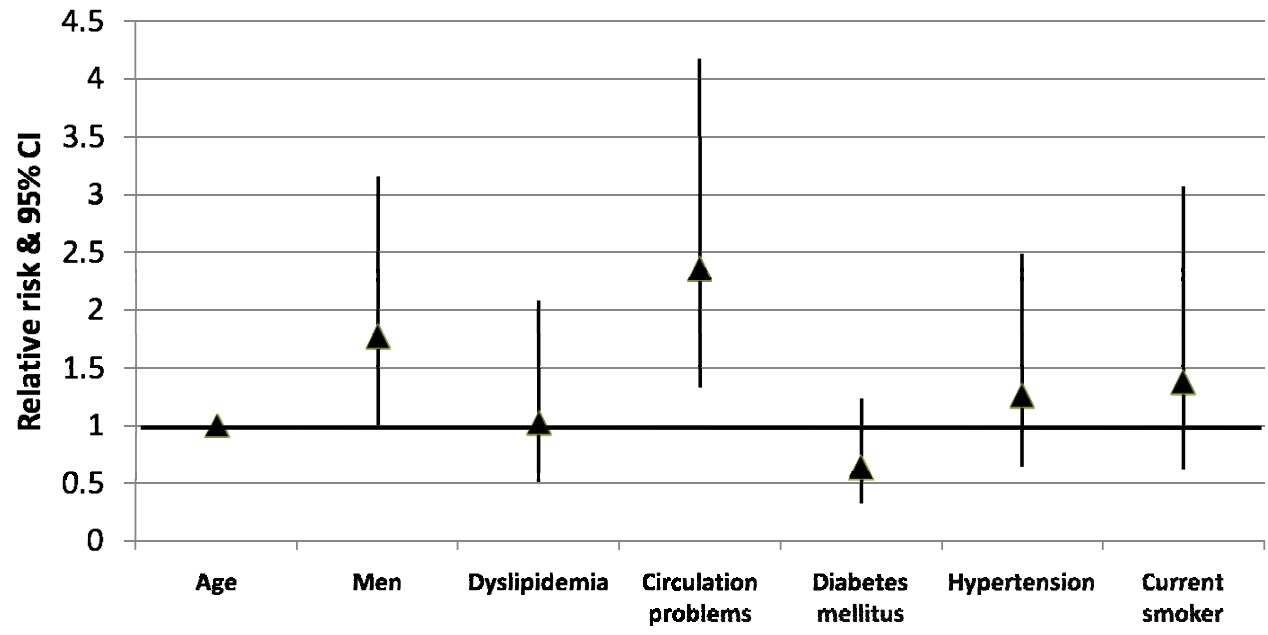

Figure I

Relative risk and $95 \%$ confidence interval of an incident CVD event among individuals with subclinical atherosclerosis. Log likelihood $=3$ |3.8, R-square $=0.068$

\section{Discussion}

Several characteristics, easily obtained through self-report, distinguished respondents with subclinical atherosclerosis. Older age, male gender, and smoking were predictive of respondents with subclinical atherosclerosis. Clinically, having dyslipidemia, circulation problems, or hypertension was predictive of individuals with subclinical atherosclerosis. All of these factors can be easily and routinely assessed by primary care physicians to detect those at risk of subclinical atherosclerosis. If management of risk factors and treatment of comorbid conditions are implemented early in the process, atherosclerosis may be delayed and CVD events avoided. Subclinical atherosclerosis was also reported more often in East Coast and Midwest regions than in the Pacific regions, suggesting differential rates of imaging across the US. Several other studies of subclinical atherosclerosis imaging, including coronary artery calcium and carotid artery assessment, have had similar findings. [13,14] However, the role of these techniques in clinical practice has not yet been defined.

The incidence of CVD events was 3 times higher in respondents with subclinical atherosclerosis compared with individuals without atherosclerosis after adjustment for self-reported risk factors. Male gender, dyslipidemia, circulation problems, and hypertension distinguished respondents with subclinical atherosclerosis from individuals without atherosclerosis who later experienced an incident CVD event. Male gender and circulation problems were significant predictors of increased risk of incident CVD events in those reporting subclinical atherosclerosis. Utilizing these easily obtainable characteristics, physicians may identify individuals at risk for
CVD event who may be candidates for more aggressive diagnostic and therapeutic interventions.

The prevalence of self-reported atherosclerosis was lower in this study than that found in other studies. [15] The Multi-ethnic Study of Atherosclerosis (MESA) reported a prevalence of $34 \%$ based on plaque occurrence and $42 \%$ based on calcium score. [15] It is not surprising that the prevalence rates differ since angiographic studies are significantly more sensitive and accurate in quantifying atherosclerosis, especially subclinical atherosclerosis. However, angiographic studies using computed tomography, magnetic resonance imaging, or ultrasound and calcium scores are not done widely in routine clinical practice. The prevalence estimate of atherosclerosis from this study is an under-estimate of the true prevalence.

There are limitations to this study that should be considered. Household panels tend to under-represent the very wealthy and the very poor segments of the population and do not include military or institutionalized individuals. In addition, the determination of atherosclerosis, CVD event, dyslipidemia, hypertension, circulation problems, and diabetes was made based upon self-report rather than clinical or laboratory measures. Nor was the method of assessment available for those reporting subclinical atherosclerosis. Fatal CVD events could not be ascertained in this survey, so the incidence of CVD events may be under-estimated in this study. The proportion of respondents reporting a diagnosis of atherosclerosis was low in this study; many more respondents may have had subclinical atherosclerosis that was not symptomatic or diagnosed. 


\section{Conclusion}

Atherosclerosis is a chronic and progressive disease whose optimal prevention requires lifelong attention to diet, exercise, smoking abstinence, and aggressive risk factor identification and treatment. Several characteristics, easily obtained through self-report, may distinguish respondents more likely to have subclinical atherosclerosis. Selfreport of subclinical atherosclerosis identifies individuals at very high CVD risk who are candidates for more aggressive risk factor intervention, including cholesterol and blood pressure reduction, management of blood glucose, and weight loss.

\section{Competing interests}

SHIELD is supported by funding from AstraZeneca Pharmaceuticals LP.

JGR is an advisory board member who received an honorarium from AstraZeneca Pharmaceuticals LP. KMF received research funds from AstraZeneca Pharmaceuticals LP to conduct the analysis and prepare the manuscript. MFB and SG are employees and stockholders of AstraZeneca LP.

\section{Authors' contributions}

JGR participated in the design of the study and helped to draft the manuscript. KMF participated in the design of the study, managed the statistical analysis, and drafted the manuscript. MFB assisted with drafting the manuscript. SG conceived of the study, coordinated the data collection, and assisted in drafting the manuscript. All authors read and approved of the final manuscript.

\section{Acknowledgements}

Members of the SHIELD Study Group are: Harold Bays, MD, Louisville Metabolic and Atherosclerosis Research Center, Louisville, KY; Debbra D. Bazata, RD, CDE, St. Luke's Primary Care South, Overland Park, KS; James R. Gavin III, MD, PhD, Emory University School of Medicine, Atlanta, GA; Andrew J. Green, MD, Midwestern Endocrinology, Overland Park, KS; Sandra J. Lewis, MD, Northwest Cardiovascular Institute, Portland, OR; Michael L. Reed, PhD, Vedanta Research, Chapel Hill, NC; Jennifer G. Robinson, MD, University of lowa, lowa City, IA; and Helena W. Rodbard, MD, Rockville, MD. Tina Fanning of Vedanta Research, Chapel Hill, NC, also contributed to this report, performing data collection and analysis. SHIELD is supported by funding from AstraZeneca Pharmaceuticals LP. The sponsor did not have a role in the study design, analysis, interpretation of the data, or in writing the manuscript except through the authors SG and MFB.

\section{References}

I. Rosamond W, Flegal K, Furie K, Go A, Greenlund K, Haase N, Hailpern SM, Ho M, Howard V, Kissela B, Kittner S, Lloyd-Jones D, McDermott M, Meigs J, Moy C, Nichol G, O'Donnell C, Roger V, Sorlie P, Steinberger J, Thom T, Wilson M, Hong Y, for the American Heart Association Statistics Committee and Stroke Statistics Subcommittee: Heart Disease and Stroke Statistics--2008 Update: A Report From the American Heart Association Statistics Committee and Stroke Statistics Subcommittee. Circulation 2008, I I 7:e25-el46.

2. Toth PP: Subclinical atherosclerosis: what it is, what it means and what we can do about it. Int J Clin Prac 2008, 62: I246-I 254.
3. Faxon DP, Creager MA, Smith SC, Pasternak RC, Olin JW, Bettman MA, Criqui MH, Milani RV, Loscalzo J, Kaufman JA, Jones DW, Pearce WH, American Heart Association: Atherosclerotic vascular disease conference: executive summary. Circulation 2004, 109:2595-2604.

4. US Department of Health and Human Services: Healthy People 2010: With Understanding and Improving Health and Objectives for Improving Health Washington, DC: Government Printing Office; 2000.

5. US Department of Health and Human Services: A Public Health Action Plan to Prevent Heart Disease and Stroke Atlanta, GA: Centers for Disease Control and Prevention; 2003.

6. Veazie MA, Galloway JM, Matson-Koffman D, LaBarthe DR, Brownstein JN, Emr M, Bolton E, Freund E Jr, Fulwood R, Guyton-Krishnan J, Hong Y, Lebowitz M, Ochiai E, Schoeberl M, Robertson RM: Taking the initiative: implementing the American Heart Association guide for improving cardiovascular health at the community level: healthy people 2010 heart disease and stroke partnership community guideline implementation and best practices workgroup. Circulation 2005, I I 2:2538-2554.

7. Pearson TA, Blair SN, Daniels SR, Eckel RH, Fair JM, Fortmann SP, Franklin BA, Goldstein LB, Greenland P, Grundy SM, Hong Y, Miller $\mathrm{NH}$, Lauer RM, Ockene IS, Sacco RL, Sallis JF Jr, Smith SC Jr, Stone $\mathrm{NJ}$, Taubert KA: AHA guidelines for primary prevention of cardiovascular disease and stroke: 2002 update: Consensus panel guide to comprehensive risk reduction for adult patients without coronary or other atherosclerotic vascular diseases. Circulation 2002, 106:388-391.

8. Goldstein L, Adams RJ, Becker K, Furberg CD, Gorelick PB, Hademenos G, Hill M, Howard G, Howard VJ, Jacobs B, Levine SR, Mosca L, Sacco RL, Sherman DG, Wolf PA, del Zoppo GJ: Primary prevention of ischemic stroke. A statement for healthcare professionals from the Stroke Council of the American Heart Association. Stroke 200I, 32:280-299.

9. Smith JSC, Allen J, Blair SN, Bonow RO, Brass LM, Fonarow GC, Grundy SM, Hiratzka L, Jones DH, Krumholz HM, Mosca J, Pasternak RC, Pearson T, Pfeffer MA, Taubert KA: AHA/ACC guidelines for secondary prevention for patients with coronary and other atherosclerotic vascular disease: 2006 update: Endorsed by the National Heart, Lung, and Blood Institute. J Am Coll Cardiol 2006, 47:2130-2139.

10. Bays HE, Bazata DD, Clark NG, Gavin JR III, Green AJ, Lewis SJ, Reed ML, Stewart W, Chapman RH, Fox KM, Grandy S: Prevalence of selfreported diagnosis of diabetes mellitus and associated risk factors in a national survey in the US population: SHIELD (Study to Help Improve Early evaluation and management of risk factors Leading to Diabetes). BMC Public Health 2007, 7:277.

II. Clark NG, Fox KM, Grandy S, for the SHIELD Study Group: Symptoms of diabetes and their association with the risk and presence of diabetes. Diabetes Care 2007, 30:2868-2873.

12. US Census Bureau: Annual Supplement to the Current Population Survey: Census Bureau Resident Population Estimates of the United States Washington, DC: US Census Bureau; 2003.

13. Budoff MJ, Achenbach S, Blumenthal RS, Carr JJ, Goldin JG, Greenland P, Guerci AD, Lima JAC, Rader DJ, Rubin GD, Shaw LJ, Wiegers SE: Assessment of coronary artery disease by cardiac computed tomography: a scientific statement from the American Heart Association Committee on Cardiovascular Imaging and Intervention, Council on Cardiovascular Radiology and Intervention, and Committee on Cardiac Imaging, Council on Clinical Cardiology. Circulation 2006, I | 4:|76|-I79|.

14. Lorenz MW, Markus HS, Bots ML, Rosvall M, Sitzer M: Prediction of clinical cardiovascular events with carotid intima-media thickness. A systematic review and meta-analysis. Circulation 2007, II 5:459-467.

15. Nasir K, Katz R, Takasu J, Shavelle DM, Detrano R, Lima JA, Blumenthal RS, O'Brien K, Budoff MJ: Ethnic differences between extracoronary measures on cardiac computed tomography: multi-ethnic study of atherosclerosis (MESA). Atherosclerosis 2008, 198:104-II4.

\section{Pre-publication history}

The pre-publication history for this paper can be accessed here:

http://www.biomedcentral.com/1471-2261/9/46/prepub 